\title{
1.16
}

\section{Cidadania e democracia sanitária: refletindo sobre o direito à saúde da população "trans" numa perspectiva de integralidade}

Citizenship and Health Democracy: reflecting on the health right of the "trans" population in an integrality perspective

\section{Adriana Ribeiro Rice Geisler}

Advogada. Psicóloga. Doutora em Teoria do Estado e Direito Constitucional. Docente e pesquisadora do Instituto de Pesquisa Clínica Evandro Chagas (IPEC), da Fundação Oswaldo Cruz (Fiocruz). Rio de Janeiro, Brasil.

\section{Valéria Lagrange Moutinho dos Reis}

Psicóloga. Sanitarista. Mestre em Saúde Pública. Pesquisadora do Instituto de Pesquisa Clínica Evandro Chagas (IPEC), da Fundação Oswaldo Cruz (Fiocruz). Rio de Janeiro, Brasil

\section{Stephan Sperlin}

Médico. Graduado em Medicina e Ciências Médicas pela Faculdade de Medicina da Fundação do ABC. São Paulo, Brasil.

Resumo: Historicamente, as demandas da população "trans" vêm sendo atendidas na medida em que se reduzem à infecção por HIV/DST ou, mais recentemente, se vinculam às práticas relacionadas ao uso de hormônios e próteses para transformações corporais, configurando as duas grandes linhas de cuidado disponíveis no sistema de saúde para essa população. Nesse contexto, a despeito do que nos fala a Política Nacional de Saúde Integral de Lésbicas, Gays, Bissexuais, Travestis e Transexuais, pode-se dizer que a política de atenção à saúde para essa população, estaria configurando um duplo estigma? Este trabalho teve como objetivo realizar uma intervenção junto à população de travestis e/ou transexuais (TT) da Baixada Fluminense (Rio de Janeiro, Brasil), com o propósito de refletir sobre suas necessidades de saúde, numa perspectiva de integralidade. Escolheu como estratégia metodológica as comunidades ampliadas de pesquisa. Elegeu-se o campo empírico em função da maior vulnerabilidade social da população local e da existência de movimentos sociais de "TT" receptivos à pesquisa. Foram realizadas rodas de conversa com o grupo constituído pelas "TT" da localidade. Ao final de cada "roda de conversa", as discussões foram sistematizadas, tornando possível identificar: 1) aspectos sociais, culturais e comportamentos associados à infecção do HIV, incluindo estigma e preconceito. 2) as demandas de travestis e transexuais no que diz respeito à prevenção e ao tratamento das DST/HIV-AIDS/HV e às transformações corporais; 3) as demandas de travestis e transexuais por acesso aos serviços de saúde de maneira ampla e numa perspectiva de integralidade.

Palavras-chaves: integralidade; travestis e transexuais; direito à saúde.

Key-words: integrality; transvestites and transsexuals; health right. 


\section{Introdução}

Desde a década de 1980, o enfrentamento do HIV/aids vem se constituindo na esteira da parceria entre as instâncias governamentais e os movimentos sociais vinculados à defesa dos direitos da população de LGBT. A criação da Política Nacional de Saúde Integral de Lésbicas, Gays, Bissexuais, Travestis e Transexuais (PNSI LGBTT) é um marco nesse percurso, sendo fundamental tanto no que se refere ao controle da epidemia de DST e HIV/aids quanto no próprio processo de consolidação do SUS. As questões apresentadas pelo documento revelam sua preocupação com uma política de saúde transversal e o reconhecimento da complexidade dessa população visando à ampliação do "conjunto de suas demandas em saúde".

Essas ações, no entanto, não podem desconsiderar o que essas populações dizem de si mesmas e o que pensam para si mesmas. A pesquisa Protagonismo "trans", processo transexualizador e atenção em HIV/aids: repensando políticas de saúde para (e com) travestis e transexuais numa perspectiva de integralidade incentiva o protagonismo desses atores na construção de políticas públicas para o setor ao mapear e sistematizar as demandas de saúde e as soluções encontradas por travestis e transexuais na busca de intervenções terapêuticas.

Ao analisar o itinerário terapêutico da população de travestis e transexuais (TT) no seu duplo estigma (DST/HIV-aids/hepatites virais e transformações corporais (ESP), a pesquisa se baseia em outros estudos que mostram que não é fácil o acesso de uma pessoa transexual ao sistema de saúde (Schramn et al., 2011).

Por exemplo, a dificuldade de ser reconhecido pelo nome social causa no sujeito constrangimento e desconfiança na relação com os serviços. O despreparo de profissionais, principalmente os responsáveis pelo acolhimento ou seja, o primeiro contato com o serviço, ainda se traduz em estranhamento e preconceito, nem sempre velado, ao transexual que demanda atendimento.

E ao mesmo tempo em que são sinalizados avanços na atenção a essa população pelo SUS, através da hormonioterapia e das cirurgias de transgenitalização, "não se pode perder de vista que os argumentos que legitimam aquela mesma intervenção médico-cirúrgica se sustentam em um arcabouço médicopsiquiátrico patologizante da transexualidade" (Schramn et al., 2011, p. 73-4). 
A patologização é a porta de entrada que lhes garante o acesso ao SUS. Os serviços, que não são organizados de forma inclusiva, só enxergam o que necessita ser consertado, em uma lógica de higienização e controle. Eles não conseguem acolher o diferente, o que está fora da norma, ou seja, as pessoas que não se encaixam nos padrões pré-estabelecidos. No caso da população TT, "sujeitos que não se conformam em e com seus corpos" (Pereira, 2006, p. 471)

Esses sujeitos têm que se submeter a esse arcabouço médico-psiquiátrico, que inclui terapia compulsória, por que Ihes é negada a autonomia e o direito de decidirem sobre seus próprios corpos. Cabem aos especialistas a avaliação e a decisão, disciplinadora em uma perspectiva foucaultiana, sobre a sexualidade e o corpo da população "trans" que busca acolhimento nos serviços de saúde.

Mas, o que quer a população "trans"? O outro é sempre sua dimensão de singularidade; ninguém é o Outro. De acordo com Haraway, os saberes subalternos, assujeitados, o "outro", sempre pode falar sobre si mesmo. (Haraway, 1988)

É essa aposta em novas produções desejantes, micropolíticas, que passeremos a descrever a seguir. Investimento cidadão, instituinte, manifesto na reapropriação de espaços/saberes/poderes, em um processo de construção de políticas públicas consequentes e transformadoras da realidade de saúde da população "trans".

\section{A patologização da transexalidade: ciência médica, direito e heteronormatividade.}

Pode-se dizer com Foucault que os modos de vida "trans" se opõem a noção de identidade ou grupos identitários, posto que são plurais, dinâmicos, históricos, mutáveis, singulares. Todavia, com o mesmo autor, aprendemos que o direito e a medicina constituem domínios de produção de conhecimento que se insinuam para a produção de verdade e o controle da vida. Voltam-se esses dois campos de conhecimento, segundo o autor, para a solidificação de processos de assujeitamento e exclusão, pelos quais o direito de viver é negado cotidianamente. (Foulcault, 1992. 1999). O Estado - e a norma - portanto, funcionam como importante máquina de captura que retira a produção desejante de ser o que se é. (Guattari e Deleuze, 2012)

As demandas da população "trans" as mais variadas possíveis, são tão antigas quanto os discursos sobre a sua (des)legitimação. Desde Harry Benjamim, o 
indivíduo-transexual é aquele que "verdadeiramente" se adequa à normalização binária inscrita na lógica jurídica da igualdade (Ventura, 2010). Paradoxalmente, no todos são iguais, (porém) perante a lei (a minha lei, a lei da heteronormatividade), apagam-se as diferenças. O transexual é mais indivíduo, portador de direitos deveres, quanto mais um igual a mim ele for, ainda que como cópia imperfeita da cisheteronormatividade.

O gênero passou a ser uma categoria diagnóstica no início dos anos 80 , quando da tipificação da transexualidade nos manuais internacionais de diagnóstico, como um "transtorno de identidade de gênero". O sistema de nomenclatura psiquiátrico norte americano, conhecido como Manual Diagnóstico e Estatístico dos Transtornos Mentais (DSM), em sua quarta versão, foi o primeiro a incluir a transexualidade como uma disforia de gênero no que foi seguido, sem maiores questionamentos, pelo Código Internacional de Doenças (CID).

Foi, portanto, a incorporação de uma categoria cultural como categoria de gênero que permitiu a inclusão da transexualidade no rol das doenças identificáveis com transtornos mentais.

A patologização da transexualidade baseia-se no pressuposto de que os gêneros são determinados pelo dimorfismo dos corpos, tendo na dinâmica presençaausência do pênis o referencial lógico na determinação da identidade de gênero. A existência de um pênis é condição necessária para determinar a identidade de gênero masculino. Substituído o pênis por um orifício vaginal, tem-se a identidade de gênero feminina. A partir (e fora) desses eixos, tidos como tipos ideais, ergue-se a suposição médica de gêneros não saudáveis.

A patologização do gênero é, portanto, sustentada pelo discurso médico hegemônico que vincula sexo e gênero. Está, assim, o saber/poder médico a orientar as políticas públicas de saúde e o exercício da cidadania para essa parcela da população. Vale dizer, que a sujeição das identidades de gênero às determinações da ciência médica encontra respaldo no discurso jurídico-legal, de tendência universalizante, mas sujeito a particularizações.

Dentro da sistemática jurídico-legal, é a noção de indivíduolpessoa que confere ao sujeito de direito sua referência antropológica. No âmago de uma relação jurídica, seja ela natural ou jurídica, somente a pessoa pode ser sujeito de direitos porque a ela correspondem direitos e obrigações. O direito se constitui, portanto, à base de 
uma noção de sujeito que "se individualiza na estrutura abstrata da relação jurídica" (Souza Junior, 1994: 137).

Se é o indivíduo o portador de direitos e deveres definidos na Constituição e nas leis, os chamado "direitos subjetivos" nada mais são do que a anexação ao nível individual de um direito de caráter geral - o "direito objetivo".

Note-se que como elemento lógico da ideia do direito, para cada sujeito corresponderá necessariamente, de acordo com possibilidade mesma da relação jurídica, outro sujeito e uma ordem previamente definida. Em torno de um discurso universalizante, os objetos jurídico e material sobre os quais poderá versar a lide já estão determinados, assegurando-se a igualdade jurídico-formal e a liberdade contratual como estruturantes da relação jurídica em questão.

Concebido como exterior à estrutura do direito, o sujeito, a quem se atribui a qualidade de "ativo", é, na realidade, o destinatário das normas jurídicas. Nessa dinâmica, é possível perceber a consistência de determinados aspectos que vão imprimir uma essência psicológica na constituição do sujeito jurídico. Trata-se de reduzir o sujeito a um objeto e negá-lo enquanto diferença, enquanto singularidade. (Marques Neto, 1994, 57)

No todos são iguais, (porém) perante a lei (a minha lei, a lei da cisheteronormatividade), apagam-se as diferenças. Paradoxalmente, o transexual é mais indivíduo, portador de direitos deveres, quanto mais um igual a mim ele for, ainda que como cópia imperfeita.

Pode-se dizer que os direitos até hoje reconhecidos nessa direção, se, por um lado tem garantido o acesso a alguns dos procedimentos requeridos, por outro o fazem sobre a insígnia do preconceito e da exclusão. Travestidos de reconhecimento, os discursos de legitimação se impuseram mais como prática de controle e tática de invisibilidade do que de alteridade. Quanto menos "trans" ele for, quanto menos transitar entre o feminino e o masculino, quanto mais fixar sua identidade de gênero ao sexo biológico mais poderá circular, seguramente, como um de nós... É a norma que estipula o acesso das pessoas à categoria de humano. 


\section{Integralidade como atenção às necessidades de saúde de grupos específicos: o que quer a população "trans"?}

Sabemos que as duas grandes linhas de cuidado disponíveis no sistema de saúde brasileiro para a população "trans" dizem respeito à prevenção e controle do HIV/AIDS e às chamadas transformações corporais. $O$ enfrentamento da epidemia do HIV/AIDS é uma preocupação de saúde pública desde a década de 80. Já o chamado "processo transexualizador" no Sistema Único de Saúde brasileiro reponde, desde fins da década de 90, ao aumento da demanda de auxílio médico por parte de transexuais de ambos os sexos nos serviços públicos de saúde, inclusive pela realização de cirurgias de transgenitalização.

Em 1997, o Conselho Federal de Medicina brasileiro, através da resolução 1.482, aprovou a realização dessas cirurgias. Em 2002, a resolução de 1997 foi revogada pela resolução 1.652 que, considerando o estágio atual de tratamento dos casos e o bom resultado estético e funcional das neocolpovulvoplastias e/ou procedimentos complementares, resolve que as cirurgias para adequação do fenótipo masculino para feminino podem ser praticadas em hospitais públicos ou privados, independentemente da atividade de pesquisa, mas seguindo os critérios de acompanhamento já estabelecidos. No caso da neofaloplastia e/ou procedimentos complementares, se manteve a condição de sua realização em hospitais universitários ou hospitais públicos adequados para a pesquisa devido às dificuldades técnicas ainda presentes. (Amaral, 2011)

A publicação destas resoluções mais uma vez (re)colocaram a população trans na agenda das políticas de saúde, constituindo-se como mais um esforço no sentido de institucionalizar a assistência a essa população. Todavia:

"quando se olha para travestis e transexuais, ainda se olha como um grupo de risco. Só se enxerga a cara da AIDS. Vulnerabilidade é só um nome bonito. (Já quando se trata de processo transexualizador) $A$ cirurgia é um ponto; não é "o" processo transexualizador'. (ator A)

Portanto, apesar dos ganhos relativos aos processos de modificação corporal e ao acesso à assistência, exames e tratamentos das DST/HIV/HV, muito ainda há que se formular, considerando as necessidades, as demandas e o próprio protagonismo dessa parcela da população na elaboração de políticas que efetivamente garantam o seu acesso integral à saúde. 
Neste sentido, para além de um princípio organizativo que visa a oferecer cobertura indiscriminada às necessidades de saúde da pessoa - de forma hierarquizada, isto é, através dos três níveis de atenção, e mais ampla possível - o conceito de integralidade, tal como o tilizamnos aqui, nos lança à ideia de abrangência.

Tal perspectiva (de abrangencia do cuidado) reforça a centralidade da pessoa e de sua dinâmica biopsicossocial na compreensão dos processos que a levaram a adoecer, e no que pode ser feito para reabilitá-la, prevenir novos episódios e prevenir comunitariamente o agravo. Noutras palavras, abrangencia respeita e considera culturidades, saberes, atores e protagonistas sociais do processo saúde e doença.

Para algumas lideranças "trans", quando se trata especificamente do processo transexualizador.
"A hormonioterapia, por exemplo, é uma demanda urgente. O mau uso de seringas nos procedimentos de transformação corporal realizados pelas chamadas bombadeiras são um risco cada vez mais presente à exposição às DST, à aids e às hepatites virais". (ator B)
"A compra e a distribuição gratuita de hormônios e a ampliação da rede de ambulatórios para esse fim configurariam passos importantes na solução desse problema" (exposição às DST, à aids e às hepatites virais pelo mau uso de seringas) (ator $\mathrm{C}$ )
"Estética é saúde" e a "hormonioterapia" é uma demanda urgente. A cirurgia é um ponto; não é "o" processo transexualizador." (ator D)

Além das considerações, avaliações e propostas em relação a essas duas frentes já, de alguma forma, incorporadas pelo sistema de saúde, as mesmas lideranças foram unânimes em apontar a necessidade de construção de outras políticas para (e com) essa população que, permanentemente, sofre resistências e preconceito nos serviços de saúde.

"Imagine você chegar em uma UPA toda montada, maqueada, e ser chamada pelo nome de registro? Os atendentes se negam a te chamar pelo nome social. É um constrangimento." (Ator A)

"É necessário incluir de verdade as travestis e transexuais na rede oficial de saúde". (ator C)

"Os profissionais de saúde precisam entender quais são as nossas necessidades específicas. Precisamos pensar em alguns cursos de formação para esses profissionais. Assim poderemos contribuir para a nossa visibilidade social, especialmente entre esses profissionais" (ator D) 
"Não queremos uma igualdade baseada na heterossexualidade. Nossas lutas agora não devem ser mais pela igualdade no acesso, mas pela equidade no atendimento". (ator A)

Tanto quanto a propostas incialmente recolhidas, ficou-nos a certeza de que a construção conjunta de uma metodologia radicalmente participativa, não apenas permite um "diagnóstico" das vulnerabilidades e necessidades de saúde dessa população, mas também é capaz de incentivar o protagonismo desses atores na construção de políticas públicas para o setor. Na perspectiva de uma radical democracia sanitária que, no resgate do princípio da diferença, amplia a cidadania desses atores, a noção de integralidade ganha o sentido de abrangência.

Considera-se fundamental reduzir as distâncias entre produção de conhecimento e saúde pública; entre ciência e senso comum; entre o que se constrói na "academia" sobre a população pesquisada e o que o próprio sujeito, criativamente, diz/constrói de si mesmo, de sua situação de vulnerabilidade e em termos de proposta de políticas públicas de saúde. No dizer de uma importante liderança: "uma política se constrói do micro para o macro. E é isso que queremos: participar mais diretamente" (ator A).

\section{Considerações finais}

Vimos que, desde a década de 1980, o enfrentamento da epidemia do HIV/AIDS vem se constituindo na esteira da parceria entre as instâncias governamentais e os movimentos sociais vinculados à defesa dos direitos da população de LGBT. A criação da Política Nacional de Saúde Integral de lésbicas, gays, bissexuais, travestis e transexuais (PNSI LGBT) é um marco nesse percurso, sendo fundamental tanto no que se refere ao controle da epidemia de DST, HIV/aids quanto no próprio processo de consolidação do Sistema Único de Saúde (SUS). Demonstra-se, já de início, que a implementação de qualquer política comprometida com o SUS, posto que sustentada na construção coletiva e cidadã, não pode prescindir do protagonismo dos sujeitos mais diretamente envolvidos por ela. Nessa lógica, "Gestão, Vigilância e Prevenção e Controle das DST, Aids e Hepatites Virais" revelam-se como processos indissociáveis.

As questões apresentadas pelo documento do Ministério da Saúde de 2010 revelam a sua preocupação com uma política de saúde transversal e o reconhecimento da complexidade das "especificidades de lésbicas, de gays, de 
bissexuais, de travestis e de transexuais no que diz respeito ao processo saúde-doença" e das suas vulnerabilidades, tornando possível "ampliar o conjunto de suas demandas em saúde". Neste contexto, travestis e transexuais constituem uma parcela ainda mais excluída e demandam ações conjuntas voltadas para seus problemas cotidianos. Historicamente, essas demandas vêm sendo pouco a pouco atendidas na medida em que se relacionam à infecção por HIV/DSTs ou às práticas relacionadas ao uso de hormônios e próteses para transformações corporais. O senso comum (que inclui os profissionais da saúde), ainda que avance para o conceito de vulnerabilidade, permanece reduzindo essas populações a "categorias de risco". Torna-se fundamental sustentar ações que apontem para a relevância do olhar integral de que nos fala a PNSI LGBT.

Essas ações, no entanto, não podem desconsiderar o que essas populações dizem de si mesmas e o que pensam para si mesmas. Travestis e transexuais vêm em um processo crescente de protagonismo em suas demandas. São conhecidas as trajetórias de Janaína Dutra, no Ceará, e de Brenda Lee, em São Paulo. No Rio de Janeiro, Charla, da ONG Charlate, e Geovana Baby, da ASTRAL, destacaram-se como precursoras das lutas das travestis no Rio de Janeiro.

Com uma trajetória de vida marcada pelo engajamento e pela mobilização da resistência e da luta das travestis por seus direitos humanos, Janaína foi a primeira ativista travesti que dialogou com o Ministério da Saúde, no então Programa Nacional de DST/Aids, para a constituição de políticas públicas de prevenção e assistência à saúde. Brenda Lee foi quem primeiro acolheu em sua casa as transexuais e travestis com aids abandonadas pela família.

Considerando essas experiências, e mesmo inspirados por essas estórias, esta pesquisa não apenas tem se pautou pelo "diagnosticar" a realidade estudada. O levantamento, a descrição, o olhar do pesquisador capaz de subsidiar ações governamentais de prevenção e controle epidemiológico, evidentemente, tomaram parte da pesquisa. Entretanto, sem abandonar a objetividade científica, o trabalho vem assumindo sua implicação de comprometimento com a população de travestis e transexuais. Busca-se avançar no sentido de fortalecer novas tecnologias de gestão que, por se sustentarem na "redução das distâncias entre produção de conhecimento e saúde pública", impactam na construção de políticas públicas consequentes e transformadoras da realidade de saúde, especialmente (mas não apenas) na área de DST/HIV/aids/hepatites virais e das 
transformações corporais. Certamente, novas tecnologias de prevenção implicam em novas tecnologias de Gestão.

Aposta-se na micropolítica. A sociedade de controle é poderosa, mas a potência de resistir será sempre seu efeito colateral. Não há assujeitamento sem resistência! Novas produções desejantes são sempre possíveis.

É possível - e fundamental, portanto - que sejam utilizadas e desenvolvidas metodologias de fortalecimento de políticas e ações transversais, alicerçadas na construção de uma rede que articula os saberes práticos (Foucault), "agonísticos", os "saberes localizados" (Haraway, op. cit.) de quem vive a experiência, e os saberes científicos, oriundos das disciplinas epistêmicas que tratam desta temática.

\section{Referências}

AMARAL, Daniela Murta e ARÁN, Márcia Ramos (orientador) O desafios da despatologização da transexualidade: reflexões sobre a assistência a transexuais no Brasil. Tese. Pós Graduação em Saúde Coletiva - Ciências Humanas. Instituto de Medicina Social - UERJ. 2011.

BENTO, Berenice. A reinvenção do corpo: sexualidade e gênero na experiência transexual. Rio de Janeiro: Garamond, 2006.

BRASIL. Ministério da Saúde. Política Nacional de Saúde Integral de Lésbicas, Gays, Bissexuais, Travestis e Transexuais. Brasília: MS, 2010.

FOUCAULT, M. Microfísica do Poder. Rio de Janeiro: Graal, 1992.

A verdade e as formas jurídicas. Rio de Janeiro: Nau Ed., 1999.

GUATTARI, Felix e DELEUZE, Gilles. Mil platôs. (v. 5): Capitalismo e esquizofrenia. São Paulo : Ed. 34, 2012.

HARAWAY, Donna. Situated Knowledges: the Science Question in Feminism and the Privilege of Partial Perspective, Feminist Studies, 14: 575-99, 1988.

MARQUES NETO. Para a Compreensão do Sujeito Jurídico: Uma Leitura Transdisciplinar. In: Instituto dos Advogados Brasileiros. Seleções Jurídicas. Rio de Janeiro: Instituto dos Advogados Brasileiros, 1994.

PEREIRA, Pedro Paulo G. A Teoria Queer e a Reinvenção do Corpo. Cadernos Pagu, (27): 469-477, jul./dez. 2006.

SCHRAMN, F.R.; Barboza H.H.; Guimarães A. A Moralidade da Transexualidade: Aspectos Bioéticos e Jurídicos. Revista Redbioética/UNESCO, 1(3): 66-77, jan./jun., 2011.

SOUZA JR. J.G. de. A Constituição do Sujeito Jurídico. In: Instituto dos Advogados Brasileiros. Seleções Jurídicas. Rio de Janeiro: Instituto dos Advogados Brasileiros, 1994.

STARFIELD, Barbara. Is primary care essential? Lancet, 344:1129-33. 1994.

VENTURA, Mírian. A transexualidade no tribunal: saúde e cidadania. Rio de Janeiro : Ed. UERJ, 2010. 